\title{
Associations among the food environment, diet quality and weight status in Cree children in Québec
}

\author{
Shauna M Downs ${ }^{1}$, Amber Arnold ${ }^{1}$, Dru Marshall ${ }^{2}$, Linda J McCargar ${ }^{1}$, Kim D Raine ${ }^{3}$ \\ and Noreen D Willows ${ }^{1, *}$ \\ ${ }^{1}$ Department of Agricultural, Food and Nutritional Science, 4-10 Agriculture/Forestry Centre, University of \\ Alberta, Edmonton, Alberta, Canada, T6G 2P5: ${ }^{2}$ Faculty of Physical Education and Recreation, University of \\ Alberta, Edmonton, Alberta, Canada: ${ }^{3}$ Centre for Health Promotion Studies, School of Public Health, University \\ of Alberta, Edmonton, Alberta, Canada
}

Submitted 9 December 2007: Accepted 18 November 2008: First published online 15 January 2009

\begin{abstract}
Objective: To explore the relationship among children's diet quality, weight status and food environment in subarctic Canada.

Design: In the cross-sectional study, children's BMI was calculated, diet quality was assessed using three $24 \mathrm{~h}$ dietary recalls and children were asked about their home food environment and source of meals.

Setting: Two Aboriginal Cree communities in northern Québec.

Subjects: Two hundred and one children in grades 4-6.

Results: The majority $(64 \cdot 2 \%)$ of children were overweight $(29 \cdot 9 \%)$ or obese $(34 \cdot 3 \%)$. Weight status was not associated with reported restaurant meal frequency or the home food environment. The $18 \%$ of children who consumed three or more restaurant meals in the three days of recall consumed, on average, $2004 \mathrm{~kJ}$ ( $479 \mathrm{kcal})$ more energy daily than children consuming no restaurant meals and had higher intakes of fat, saturated fat, $\mathrm{Ca}$ and soda. Most foods contributing to energy and dietary fat were energy-dense market foods of low nutritional value such as sweetened beverages and snack foods. Only $68 \%$ of children reported often having fruits and vegetables in the home and $98.5 \%$ of children consumed less than 5 fruits and vegetables daily. Many children (42.8\%) were at risk of Zn inadequacy. Only $19 \%$ of children consumed 2 or more servings of milk daily, and the mean intakes of $\mathrm{Ca}$ and vitamin $\mathrm{D}$ were below the recommended adequate intake. Traditional game meat was consumed infrequently, but contributed significantly to Fe and $\mathrm{Zn}$ intake.

Conclusions: Childhood obesity in subarctic communities prevailed in a food environment typified by high-energy-density commercial foods of low nutritional value.
\end{abstract}

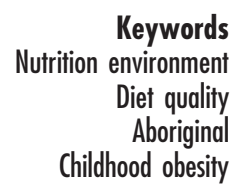

Overweight and obesity is prevalent worldwide and increasing ${ }^{(1,2)}$, likely due to the dramatic changes in both lifestyle and environment. In recent decades there has been increased accessibility to restaurants and fast-food outlets and people are spending more of their disposable income on foods away from the home. Indeed, since the late 1970s, energy intake from restaurant meals/fast foods has increased by $91 \%$ to $208 \%$ for all age groups ${ }^{(3)}$; as many as $25 \%$ of Canadians and $30 \%$ of Americans eat fast-food restaurant meals on any given day ${ }^{(3,4)}$. Meals served at restaurants and fast-food establishments are generally energy-dense (i.e. high in fat and sugar) and the portions served typically exceed recommended portion sizes ${ }^{(5)}$.

As convenience becomes a priority in many households, home-cooked meals are being replaced with prepared or away-from-home foods (i.e. take-out foods, frozen entrees and pre-cooked, pre-packaged foods $)^{(6)}$. Although the availability of foods in the home, such as fruits and vegetables, has been correlated with actual intake ${ }^{(7,8)}$, when take-out foods make a substantial contribution to the home diet, the association between home food availability and foods consumed at home may become less pronounced.

In Canada, 'Aboriginal people' is a collective name for the indigenous peoples of North America and their descendants. First Nations, the largest Aboriginal group, are diverse geographically and in language and culture. First Nations and Native American Indian children have higher rates of overweight and obesity than do children from other ethnic groups ${ }^{(1,9,10)}$. Lower literacy levels, lower education levels and lower incomes are likely underlying causes of health disparities between Aboriginal and non-Aboriginal populations ${ }^{(11)}$. The nutrition 
transition reflects the rapid change from the consumption of a cultural group's traditional foods to the adoption of a more 'Westernized diet' ${ }^{\text {(12) }}$. Aboriginal peoples undergoing the nutrition transition have an increasing proportion of their diet from store-bought foods and a decreasing proportion from traditional foods obtained from hunting, trapping, fishing and gathering ${ }^{(13,14)}$. Rates of obesity in First Nations children are thus likely the result of the loss of traditional lifestyle and the transition to market foods of low nutritional quality ${ }^{(14)}$. We completed a school-based study of First Nations children that examined the association of children's reported household food availability and restaurant/take-out meal frequency with dietary intake, risk of micronutrient inadequacy and weight status in two subarctic communities in Canada.

\section{Experimental methods}

\section{Setting}

The Active Kids Project was a cross-sectional study that examined weight status and lifestyle behaviours of students in grades 4-6 in two isolated Cree First Nation communities in the northern part of the Province of Québec; an isolated community being one having fewer than 10000 people and being more than $80 \mathrm{~km}$ from an urban centre ${ }^{(15)}$. Each community had less than 3500 people and was 90 or $561 \mathrm{~km}$ from the closest town. Both communities had two grocery stores with prices that were high relative to urban areas ${ }^{(13)}$ and three locally run restaurants that served fast foods such as poutine (French fries, brown sauce, cheese curds), French fries, hamburgers, fried battered chicken and pizza. Fried chicken, including nuggets, and French fries were sold ready-toserve in some grocery stores. The portion sizes were similar to urban fast-food restaurants.

One school from each community participated in the study, which took place in the autumn of 2004 in one community and the autumn of 2005 in the other. Children ate breakfast and lunch away from school. Prior to collecting data, students were given information sheets and parental consent forms, researchers met with school and Cree Health Board staff to discuss the study, and radio announcements were broadcast in English and Cree to inform community members about the study. Only those students with signed parental consent forms participated. English was often a second language. For this reason, information sheets and consent forms were at approximately a grade 5 reading level. To ensure cultural sensitivity, a Steering Committee of community members and Cree Health Board staff was formed that was available to explain the study to the community. The study was approved by the Human Ethics Research Board, Faculty of Agriculture, Forestry, and Home Economics, University of Alberta; The Cree Board of Health and Social Services of James Bay (Québec); and the school principals.

\section{Weight status}

Weight status was determined from measured heights and weights taken in light indoor clothing with shoes removed in a private area of the school. University research assistants were trained in the proper anthropometric measurement techniques by an exercise physiologist. BMI was calculated to the nearest $0.01 \mathrm{~kg} / \mathrm{m}^{2}$. International Obesity Taskforce age- and sex-specific cutoffs were used to categorize a child's BMI as normal, overweight or obese ${ }^{(16)}$.

\section{Dietary intake}

University researchers completed three $24 \mathrm{~h}$ dietary recalls with each child at the school on non-consecutive days, including one weekend day, using a multiple-pass interview method ${ }^{(17)}$. The recalls were conducted unannounced and researchers rotated among the participants. Probes, food models, pictures and packaging of locally sold products provided detailed information about the quantity and type of food and drinks consumed. While completing the dietary recalls each child was asked where they ate their meal and the source of their meal. This information was used to categorize restaurant/takeout food intake. Dietary information was entered into the Food Processor SQL for Windows package version 9·6.2 (Esha Research, Salem, OR, USA) and the Canadian Nutrient File (1997) was used to obtain the nutrient composition of Canadian foods and beverages. One researcher assigned the Food Processor codes for the dietary data entry, which was then checked three times to ensure accuracy of input.

Sweetened drinks (powdered fruit drinks, sports drinks and other drinks with added sugars, not including carbonated soda) were considered a single category, and a separate category was formed for sweetened carbonated soda. Fruits (excluding fruit juices) and vegetables (excluding French fries and fried potatoes) were reported as the average daily number of times a child reported eating these foods. The contribution that specific foods or food categories made to energy, energy from fat and micronutrients was calculated by summing the nutrient intakes from all three dietary recalls associated with each food or food category, then dividing by the total intake of energy, energy from fat or the specific micronutrient. When calculating the top foods contributing to energy, sweetened drinks and sweetened carbonated soda were considered together as sweetened beverages. The top five foods or food categories contributing to nutrients are reported.

\section{Restaurant and take-out food}

Children were asked if their meals were from a restaurant or take-out. The number of meals reported to be from restaurant or take-out in the three days of recall were categorized as none, 1 or 2 , or 3 or more, and were called 'restaurant meals'. 


\section{The bome food environment}

The home food environment was assessed using a food availability questionnaire adapted from the food availability portion of the University of Minnesota Project EAT (Eating Among Teens) survey ${ }^{(7)}$. Its original use was to assess the availability of foods in the homes of adolescents, and it was intended for parents to complete ${ }^{(7)}$. In the Cree study, the interviewer asked children the questions at the time of the child's first $24 \mathrm{~h}$ recall. The questionnaire was pilot-tested to ensure that it was appropriate for use with children. The interviewers did not inquire about a specific time period or season. Children were asked questions regarding the home availability of fruits and vegetables, potato chips, milk, soda pop and real fruit juice, and if vegetables were served on children's plates at dinner. 'Vegetables on the plate at dinner' was considered a proxy measure of overall vegetable intake and meal quality. For each question, children were asked to respond whether the item was never, sometimes, usually or always available. Due to the small number of responses for some categories, the 'usual' and 'always' categories were combined (referred to as 'often'), as were the 'sometimes' and 'never' categories (referred to as 'seldom') for descriptive purposes and statistical analyses.

\section{Statistical analysis}

Continuous variables are reported as means and standard deviations. For variables that were not normally distributed, the median and interquartile ranges are also reported. The $\chi^{2}$ statistic was used to test for group differences involving categorical data. Independent $t$ tests and ANOVA were used to assess group differences for continuous variables. To test for group differences for continuous variables that were not normally distributed and that were not normalized with log transformations, the Mann-Whitney $U$ test (two groups) or the KruskalWallis test (three groups) were used. General linear model (GLM) analyses were conducted to identify the independent main effects of restaurant food intake frequency and gender on anthropometry, nutrient intake and amount of food consumed. There were no significant interaction terms between the main effects for any outcome variable, so boys and girls were analysed together. The Bonferroni post hoc test was used to determine differences among restaurant meal frequency groups if the overall $F$ statistic was significant. Statistical analyses were performed using the SPSS for Windows statistical software package version $14 \cdot 0$ (SPSS Inc., Chicago, IL, USA). Statistical significance was considered at $P<0 \cdot 05$.

PC-SIDE software version 1.0 (Iowa State University, Ames, IA, USA) was used to adjust micronutrient intakes and report risk of nutrient inadequacy based on the Estimated Average Requirement (EAR) cut-point method ${ }^{(18)}$, to report the percentage of children with below adequate nutrient intakes, and to report adjusted means and standard deviations. As the Canadian Nutrient File was missing data for folate and for vitamin A for some foods, these two nutrients were excluded from the analyses.

\section{Results}

Two hundred and twenty-five students were eligible to participate; 103 children were recruited from one community and ninety-eight children were recruited from the second community ( $89 \%$ participation rate). The associations among variables were comparable for each community; therefore data were combined to increase the statistical power of the sample.

\section{Weight status}

Children had high rates of overweight (29.9\%) and obesity $(34 \cdot 3 \%)$.

\section{Housebold characteristics}

Children's average household size was 6.0 (SD 1.6) persons. Household size ranged from two persons to thirteen persons; $68.2 \%$ of households had six persons or more. The number of persons living in a household was not associated with weight status or dietary indicators (data not shown).

\section{Dietary intake}

Less than one-fifth $(19 \cdot 1 \%)$ of children consumed at least 2 servings of milk daily as recommended by Canada's Food Guide. Almost all children (98.5\%) consumed fewer than 5 fruits and vegetables daily. Table 1 identifies the top five food sources of energy, energy from fat and selected micronutrients. Traditional game meat made important contributions to children's intake of Fe and Zn despite contributing to only $3 \%$ of total energy in the diet. Adjusted means and standard deviations, and risk of inadequacy for select nutrients, are reported in Table 2.

\section{Restaurant/take-out food}

The number of restaurant meals consumed over the three days of food recalls ranged from none to five: more than three-quarters $(77 \cdot 6 \%)$ of children consumed at least one restaurant meal and $18 \cdot 4 \%$ of children consumed three or more restaurant meals. Children who ate three or more restaurant meals had higher daily intakes of energy, energy from fat and saturated fat, $\mathrm{Ca}$ and carbonated soda beverages and a lower percentage of energy from protein (Table 3).

\section{The bome food environment}

The percentage of children often having the following foods in the home was $16 \%$ for potato chips, $29 \%$ for soda pop, $65 \%$ for real fruit juices, $68 \%$ for fruits and vegetables, $87 \%$ for milk and $40 \%$ for vegetables on the dinner plate. Whereas only $22 \cdot 4 \%$ of children who seldom had potato chips at home often had soda pop at 
Table 1 Top five dietary contributors to energy, energy from fat and select micronutrients among children from two Aboriginal Cree communities in northern Québec, Canada, 2004 and 2005

\begin{tabular}{|c|c|c|}
\hline Nutrient & Food item & $\%$ of total intake \\
\hline \multirow[t]{5}{*}{ Energy } & Sweetened beveragest & $8 \cdot 9$ \\
\hline & Milk & $7 \cdot 1$ \\
\hline & White bread & $6 \cdot 4$ \\
\hline & Snack foodsł & $6 \cdot 3$ \\
\hline & Poutine§ & $5 \cdot 0$ \\
\hline \multirow[t]{5}{*}{ Energy from fat } & Snack foods $\ddagger$ & $11 \cdot 7$ \\
\hline & Milk & $7 \cdot 9$ \\
\hline & Poutines & $7 \cdot 5$ \\
\hline & Chicken & $6 \cdot 7$ \\
\hline & Pizza & $5 \cdot 9$ \\
\hline \multirow[t]{5}{*}{ Vitamin D $(\mu \mathrm{g})$} & Milk & $89 \cdot 3$ \\
\hline & Eggs & $3 \cdot 5$ \\
\hline & Ice cream & $2 \cdot 2$ \\
\hline & Butter & $1 \cdot 8$ \\
\hline & Cereal & 1.5 \\
\hline \multirow[t]{5}{*}{ Vitamin C (mg) } & Real fruit juice & $32 \cdot 9$ \\
\hline & Fruit drinks\|l & $25 \cdot 6$ \\
\hline & Oranges & $11 \cdot 7$ \\
\hline & Potato chips & $6 \cdot 9$ \\
\hline & Spaghetti sauce with beef & $2 \cdot 4$ \\
\hline \multirow[t]{5}{*}{$\mathrm{Fe}(\mathrm{mg})$} & Cereal & $20 \cdot 8$ \\
\hline & Traditional food & $16 \cdot 7$ \\
\hline & White bread & $11 \cdot 3$ \\
\hline & Boxed macaroni and cheesett & $3 \cdot 6$ \\
\hline & Beef & $3 \cdot 2$ \\
\hline \multirow[t]{5}{*}{$\mathrm{Zn}(\mathrm{mg})$} & Traditional food & $16 \cdot 8$ \\
\hline & Milk & $15 \cdot 8$ \\
\hline & Beef & $9 \cdot 6$ \\
\hline & Cereal & $8 \cdot 6$ \\
\hline & Chicken & $5 \cdot 4$ \\
\hline \multirow[t]{5}{*}{$\mathrm{Ca}(\mathrm{mg})$} & Milk & $43 \cdot 4$ \\
\hline & Cheese & $11 \cdot 9$ \\
\hline & Pizza & $5 \cdot 0$ \\
\hline & Yoghurt & $3 \cdot 5$ \\
\hline & Ice cream & $2 \cdot 7$ \\
\hline
\end{tabular}

†Sweetened beverages: punches, sweetened powdered beverages, sweetened carbonated sodas, sports drinks.

$\ddagger$ Snack foods: potato chips, corn chips, puffed corn snacks.

§Poutine: French fries, cheese curds and brown sauce.

IIFruit drinks: non-carbonated fruit punches and sweetened powdered fruitflavoured beverages with vitamin $\mathrm{C}$ added.

-Traditional foods: bear, moose, goose, moose stew, rabbit and beaver. t+This boxed prepared food is common in Canada.

home, $63 \cdot 6 \%$ of children who often had potato chips at home often had soda pop at home $(P<0 \cdot 001)$. Compared with children who seldom had fruits and vegetables at home, children who often had fruits and vegetables at home were more likely to often have vegetables on their plate at dinner $(50 \% v .31 \%, P=0 \cdot 011)$ and to often have milk in the home ( $91 \% v .77 \%, P=0 \cdot 004)$. Children who reported often having soda, real fruit juice or milk in the home consumed significantly greater quantities of these beverages than children who reported seldom having these beverages in the home $(P=0.049, P=0.024$ and $P=0 \cdot 024$, respectively). The home food environment was associated with children's dietary intake of beverages (Table 4). There were no statistical differences in the home food environment between children who were of normal weight and overweight/obese children (data not shown). Frequency of consumption of restaurant foods was comparable between all household food availability categories.

\section{Discussion}

The majority of Cree schoolchildren in the subarctic region of Québec were overweight or obese, which corroborates research that First Nations and American Indian children in Canada and the USA have excess weight ${ }^{(9,10,19)}$. Cree children had diets that were energy-dense and low in foods of high nutrient density such as fruits and vegetables. Similar observations have been made for children from other First Nations and American Indian communities $(20,21)$ and might be due, in part, to the high cost of nutrientdense foods ${ }^{(13)}$. Cree children were at risk for $\mathrm{Zn}$ inadequacy and had intakes of vitamin $\mathrm{D}$ and $\mathrm{Ca}$ below the adequate intake, which confirms findings of low intakes of several micronutrients in Aboriginal communities in Canada $^{(22,23)}$. Milk was an important source of $\mathrm{Ca}$ and vitamin D for Cree children and an increase in diet quality would be anticipated if milk consumption was increased. A positive finding of the study was the contribution of traditional game foods to both Fe and $\mathrm{Zn}$ intake. Studies in Aboriginal communities have indicated that when traditional foods are consumed, micronutrient nutrition is improved ${ }^{(22-24)}$. Traditional foods, if consumed more often, could improve children's nutrient profile.

Despite the remoteness of communities, $77 \%$ of the children consumed at least one restaurant or take-out meal during the three days of food recall, which is comparable to findings that $25 \%$ of Canadian children eat fastfood restaurant meals on any given day ${ }^{(4)}$. The foods served at fast-food establishments are generally energydense and contain high amounts of fat and sugar ${ }^{(5)}$. For this reason, when children eat restaurant meals they consume significant energy from fat and saturated fat ${ }^{(25)}$, and often have low intakes of some micronutrients ${ }^{(26)}$. Bowman et $a l .{ }^{(3)}$ reported that children who ate meals from fast-food restaurants consumed $782 \mathrm{~kJ}$ ( $187 \mathrm{kcal}$ ) more energy per day than children who did not consume these meals. In comparison, Cree children who ate the highest number of restaurant meals consumed, on average, $2004 \mathrm{~kJ}$ ( $479 \mathrm{kcal}$ ) more energy per day than children who consumed no restaurant meals. If the excess energy associated with restaurant meal intake in Cree children is not counterbalanced with increased energy expenditure, the persistence of this behaviour might result in dramatic weight gain.

There was no association between weight status and restaurant meal intake or the home food environment, which is consistent with the literature for children ${ }^{(6,27)}$. Many pre-packaged foods that are assembled in the home may have comparable nutritional quality to restaurant foods. It is therefore possible that the absence of a relationship between weight status and restaurant meal frequency reflects the quality of the foods also being consumed at home.

Cree children who often had soda, real fruit juice and milk in the home consumed significantly higher quantities 
Table 2 Estimated usual micronutrient intakes and the risk of inadequacy among children from two Aboriginal Cree communities in northern Québec, Canada, 2004 and 2005

\begin{tabular}{|c|c|c|c|c|}
\hline Micronutrient & Boys & Girls & Sexes combined & Dietary reference intake \\
\hline \multicolumn{5}{|l|}{$\mathrm{Fe}(\mathrm{mg})$} \\
\hline Mean & $15 \cdot 0$ & $11 \cdot 3^{\star \star}$ & Not applicable & \multirow{3}{*}{$\begin{array}{l}\text { EAR, } 9-13 \text { years: } \\
\text { o } 5.9 \mathrm{mg} / \mathrm{d} \\
\text { \& } 5.7 \mathrm{mg} / \mathrm{d}\end{array}$} \\
\hline $\mathrm{SD}$ & $4 \cdot 5$ & $2 \cdot 5$ & & \\
\hline$\%$ below EAR & 0.25 & $0 \cdot 18$ & & \\
\hline \multicolumn{5}{|l|}{$\mathrm{Zn}(\mathrm{mg})$} \\
\hline Mean & $8 \cdot 2$ & $7 \cdot 1$ & $7 \cdot 6$ & \multirow{3}{*}{$\begin{array}{l}\text { EAR, } 9-13 \text { years: } \\
7 \mathrm{mg} / \mathrm{d}\end{array}$} \\
\hline $\mathrm{SD}$ & $2 \cdot 6$ & $1 \cdot 6$ & $2 \cdot 1$ & \\
\hline \% below EAR & $35 \cdot 9$ & $50 \cdot 4$ & $42 \cdot 8$ & \\
\hline \multicolumn{5}{|l|}{ Vitamin C (mg) } \\
\hline Mean & $125 \cdot 5$ & $96 \cdot 8$ & $109 \cdot 7$ & \multirow{3}{*}{$\begin{array}{l}\text { EAR, 9-13 years: } \\
39 \mathrm{mg} / \mathrm{d}\end{array}$} \\
\hline SD & $60 \cdot 6$ & $45 \cdot 7$ & 54.9 & \\
\hline$\%$ below EAR & $2 \cdot 6$ & $7 \cdot 2$ & 4.9 & \\
\hline \multicolumn{5}{|l|}{$\mathrm{Ca}(\mathrm{mg})$} \\
\hline Mean & $970 \cdot 6$ & $817 \cdot 4$ & $884 \cdot 4$ & \multirow{2}{*}{$\begin{array}{l}\text { Al, } 9-13 \text { years: } \\
1300 \mathrm{mg} / \mathrm{d}\end{array}$} \\
\hline SD & $389 \cdot 0$ & $257 \cdot 4$ & $316 \cdot 4$ & \\
\hline \multicolumn{5}{|l|}{ Vitamin D $(\mu \mathrm{g})$} \\
\hline Meant & $4 \cdot 1$ & $3 \cdot 7$ & 3.9 & \multirow{2}{*}{$\begin{array}{l}\text { Al, 4-13 years: } \\
5 \mu \mathrm{g} / \mathrm{d}\end{array}$} \\
\hline SDt & $3 \cdot 0$ & $2 \cdot 4$ & $2 \cdot 7$ & \\
\hline
\end{tabular}

EAR, Estimated Average Requirement; Al, Adequate Intake; \% below EAR, the adjusted percentage of children with average nutrient intakes below the EAR; 9 , the requirements for girls in the specified age group; $\delta$, the requirements for boys in the specified age group. Mean value was significantly different from that of boys: ${ }^{* *} P<0 \cdot 01$

tindicates an unadjusted mean and standard deviation.

Table 3 The association of frequency of restaurant meals in the three days of recall with dietary variables among children from two Aboriginal Cree communities in northern Québec, Canada, 2004 and 2005

\begin{tabular}{|c|c|c|c|c|c|c|c|c|c|}
\hline \multirow{2}{*}{$\frac{\text { Variable }}{\text { Non-dietary data }}$} & \multicolumn{2}{|c|}{0 meals } & \multicolumn{2}{|c|}{1 or 2 meals } & \multicolumn{2}{|c|}{3 or more } & $P$ value & \multicolumn{2}{|c|}{ Total } \\
\hline & \multirow{3}{*}{\multicolumn{2}{|c|}{$\begin{array}{l}45 \\
40 \cdot 0\end{array}$}} & \multirow{3}{*}{\multicolumn{2}{|c|}{$\begin{array}{c}119 \\
32 \cdot 8\end{array}$}} & \multirow{3}{*}{\multicolumn{2}{|c|}{$\begin{array}{l}37 \\
32 \cdot 4\end{array}$}} & & \multirow{3}{*}{\multicolumn{2}{|c|}{$\begin{array}{l}201 \\
34 \cdot 3\end{array}$}} \\
\hline No. of children & & & & & & & $\mathrm{n} / \mathrm{a}$ & & \\
\hline \multirow[t]{2}{*}{ Obese $(\%)$} & & & & & & & 0.504 & & \\
\hline & Mean & SD & Mean & SD & Mean & SD & & Mean & SD \\
\hline Age (years) & $10 \cdot 9^{a}$ & 0.9 & $10 \cdot 7^{\mathrm{a}}$ & $1 \cdot 0$ & $10 \cdot 3^{b}$ & 0.9 & $0.033^{*}$ & $10 \cdot 7$ & $1 \cdot 0$ \\
\hline BMI $\left(\mathrm{kg} / \mathrm{m}^{2}\right)$ & $23 \cdot 8$ & $4 \cdot 7$ & $22 \cdot 9$ & $5 \cdot 2$ & $22 \cdot 6$ & $5 \cdot 1$ & 0.462 & $23 \cdot 0$ & $5 \cdot 1$ \\
\hline \multicolumn{10}{|l|}{ Energy, macronutrients and fibre } \\
\hline Energy $(\mathrm{kJ})$ & $8824^{a}$ & 2360 & $9234^{a}$ & 2807 & $10828^{b}$ & 3314 & $0 \cdot 01^{\star \star}$ & 9435 & 2883 \\
\hline (kcal) & $2109^{a}$ & 564 & $2207^{\mathrm{a}}$ & 671 & $2588^{\mathrm{b}}$ & 792 & & 2255 & 689 \\
\hline Energy from fat (kJ) & $2582^{\mathrm{a}}$ & 983 & $2774^{\mathrm{a}}$ & 979 & $3448^{\mathrm{b}}$ & 1113 & $0.001^{\star \star *}$ & 2858 & 1042 \\
\hline (kcal) & $617^{\mathrm{a}}$ & 235 & $663^{\mathrm{a}}$ & 234 & $824^{\mathrm{b}}$ & 266 & & 683 & 249 \\
\hline$\%$ energy from fat & $28 \cdot 8^{\mathrm{a}}$ & $6 \cdot 0$ & $29 \cdot 9^{a}$ & $4 \cdot 3$ & $31 \cdot 9^{b}$ & $4 \cdot 8$ & $0.009^{\star *}$ & $30 \cdot 0$ & 4.9 \\
\hline Energy from saturated fat (kJ) & $946^{\mathrm{a}}$ & 347 & $996^{\mathrm{a}}$ & 393 & $1226^{\mathrm{b}}$ & 372 & $0.005^{\star \star}$ & 1026 & 1637 \\
\hline (kcal) & $226^{a}$ & 83 & $238^{a}$ & 94 & $293^{b}$ & 89 & & $245 \cdot 3$ & 93.5 \\
\hline$\%$ energy from saturated fat & $10 \cdot 5$ & $2 \cdot 0$ & $10 \cdot 6$ & 1.9 & $11 \cdot 4$ & 1.9 & 0.075 & $10 \cdot 7$ & $1 \cdot 9$ \\
\hline$\%$ energy from protein & $15 \cdot 2^{\mathrm{a}}$ & $3 \cdot 4$ & $14 \cdot 1^{\mathrm{a}}$ & $3 \cdot 0$ & $13 \cdot 6^{\mathrm{b}}$ & $2 \cdot 7$ & $0.023^{*}$ & $14 \cdot 3$ & $3 \cdot 1$ \\
\hline$\%$ energy from carbohydrate & $57 \cdot 0$ & $7 \cdot 3$ & $57 \cdot 4$ & $5 \cdot 5$ & $56 \cdot 0$ & $5 \cdot 8$ & $0 \cdot 639$ & $57 \cdot 0$ & $6 \cdot 0$ \\
\hline Fibre $(\mathrm{g})$ & $13 \cdot 1$ & $4 \cdot 6$ & $13 \cdot 2$ & $5 \cdot 3$ & $14 \cdot 6$ & $5 \cdot 9$ & 0.439 & $13 \cdot 4$ & $5 \cdot 3$ \\
\hline \multicolumn{10}{|l|}{ Micronutrients } \\
\hline $\mathrm{Ca}(\mathrm{mg})$ & $844 \cdot 8^{\mathrm{a}}$ & $366 \cdot 1$ & $828 \cdot 9^{a}$ & $388 \cdot 0$ & $1033 \cdot 1^{b}$ & $390 \cdot 3$ & $0.04^{*}$ & $870 \cdot 0$ & $389 \cdot 5$ \\
\hline $\mathrm{Fe}(\mathrm{mg})$ & $14 \cdot 6$ & 4.9 & $13 \cdot 4$ & $5 \cdot 1$ & $15 \cdot 1$ & $6 \cdot 8$ & $0 \cdot 361$ & $14 \cdot 0$ & $5 \cdot 4$ \\
\hline $\mathrm{Zn}(\mathrm{mg})$ & $8 \cdot 9$ & $3 \cdot 4$ & $7 \cdot 6$ & $3 \cdot 3$ & $8 \cdot 2$ & $3 \cdot 4$ & 0.074 & $8 \cdot 0$ & $3 \cdot 4$ \\
\hline Vitamin D $(\mu \mathrm{g})$ & $4 \cdot 1$ & $2 \cdot 7$ & $3 \cdot 7$ & $2 \cdot 5$ & $4 \cdot 3$ & $3 \cdot 2$ & 0.565 & 3.9 & $2 \cdot 7$ \\
\hline Vitamin C (mg) & $110 \cdot 9$ & $84 \cdot 1$ & $107 \cdot 5$ & $77 \cdot 0$ & $96 \cdot 5$ & $63 \cdot 0$ & 0.534 & $106 \cdot 2$ & $8 \cdot 0$ \\
\hline \multicolumn{10}{|l|}{ Food and beverages consumed } \\
\hline Milk (ml) & 331 & 233 & 307 & 237 & 353 & 245 & $0 \cdot 700$ & 320 & 237 \\
\hline Sweetened drinks (ml) & 269 & 278 & 398 & 352 & 349 & 250 & $0.043^{*}$ & 360 & 322 \\
\hline Median (IQR) & \multicolumn{2}{|c|}{$177(55-457)$} & \multicolumn{2}{|c|}{$319(135-553)$} & \multicolumn{2}{|c|}{$277(177-457)$} & & \multicolumn{2}{|c|}{$276(118-492)$} \\
\hline Soda $(\mathrm{ml})$ & 146 & 177 & 209 & 234 & 334 & 234 & $0.000^{\star * *}$ & 218 & 229 \\
\hline Median (IQR) & \multicolumn{2}{|c|}{$60(0-249)$} & \multicolumn{2}{|c|}{$120(0-285)$} & \multicolumn{2}{|c|}{$333(134-501)$} & & \multicolumn{2}{|c|}{$176(0-334)$} \\
\hline Fruits (number) & 0.9 & 0.9 & 0.8 & $1 \cdot 0$ & $0 \cdot 7$ & 0.9 & 0.634 & 0.8 & 0.9 \\
\hline Median (IQR) & \multicolumn{2}{|c|}{$0.7(0.0-1 \cdot 5)$} & \multicolumn{2}{|c|}{$0.3(0.0-1 \cdot 0)$} & \multicolumn{2}{|c|}{$0.3(0.0-1 \cdot 0)$} & & \multicolumn{2}{|c|}{$0.3(0.0-1.0)$} \\
\hline Vegetables (number) & 0.8 & 0.7 & 0.7 & 0.7 & 0.6 & 0.9 & 0.253 & 0.7 & 0.8 \\
\hline Median (IQR) & \multicolumn{2}{|c|}{$0 \cdot 7(0 \cdot 3-1 \cdot 3)$} & \multicolumn{2}{|c|}{$0 \cdot 7(0 \cdot 0-1 \cdot 0)$} & $0.3(0.0$ & $0 \cdot 7)$ & & 0.7( & $-1.0)$ \\
\hline
\end{tabular}

n/a, not applicable; IQR, interquartile range.

Central tendency is expressed as the mean and standard deviation; in addition, the median and IQR are included for variables that were not normally distributed and the Kruskal-Wallis test was used to compare groups in these cases because data were non-parametric.

Asterisks indicate significant group differences $\left({ }^{\star} P<0.05\right.$, $\left.{ }^{\star \star} P<0.01,{ }^{\star \star \star} P<0.001\right)$. For data that were normally distributed, different superscript letters indicate significant differences among groups. 
Table 4 Child-reported household availability of food in relation to actual intake among children from two Aboriginal Cree communities in northern Québec, Canada, 2004 and 2005

\begin{tabular}{|c|c|c|c|}
\hline \multirow{2}{*}{$\begin{array}{l}\text { Reported typical daily food } \\
\text { and beverage intake }\end{array}$} & \multicolumn{2}{|c|}{ Child-reported household availability } & \multirow[b]{2}{*}{$P$ value } \\
\hline & Seldom & Often & \\
\hline & \multicolumn{2}{|c|}{ Fruit \& vegetables } & \\
\hline \multicolumn{4}{|l|}{ No. of fruit \& vegetables } \\
\hline Mean & $1 \cdot 4$ & $1 \cdot 6$ & $0 \cdot 341$ \\
\hline SD & $1 \cdot 1$ & $1 \cdot 3$ & \\
\hline \multirow[t]{2}{*}{ Median (IQR) } & $1 \cdot 0(0 \cdot 7-1 \cdot 9)$ & $1 \cdot 3(0 \cdot 7-2 \cdot 3)$ & \\
\hline & \multicolumn{2}{|c|}{ Vegetables on plate at dinner } & \\
\hline \multicolumn{4}{|l|}{ No. of vegetables } \\
\hline Mean & $0 \cdot 7$ & $0 \cdot 8$ & 0.075 \\
\hline SD & $0 \cdot 7$ & $0 \cdot 8$ & \\
\hline \multirow[t]{2}{*}{ Median (IQR) } & $0 \cdot 3(0 \cdot 0-1 \cdot 0)$ & $0 \cdot 7(0 \cdot 3-1 \cdot 2)$ & \\
\hline & \multicolumn{2}{|c|}{ Real fruit juice } & \\
\hline \multicolumn{4}{|l|}{ Real fruit juice (ml) } \\
\hline Mean & 200 & 262 & $0.024^{*}$ \\
\hline SD & 203 & 214 & \\
\hline \multirow{2}{*}{ Median (IQR) } & $150(0-327)$ & $237(83-384)$ & \\
\hline & \multicolumn{2}{|c|}{ Carbonated soda } & \\
\hline \multicolumn{4}{|l|}{ Carbonated soda (ml) } \\
\hline Mean & 190 & 285 & $0 \cdot 049^{*}$ \\
\hline SD & 194 & 288 & \\
\hline \multirow[t]{2}{*}{ Median (IQR) } & $118(0-296)$ & $198(60-434)$ & \\
\hline & \multicolumn{2}{|r|}{ ( } & \\
\hline \multicolumn{4}{|l|}{ Milk (ml) } \\
\hline Mean & 225 & 335 & $0.024^{*}$ \\
\hline SD & 152 & 245 & \\
\hline
\end{tabular}

IQR, interquartile range.

For data that were not normally distributed, the median and IQR are reported in addition to the mean and standard deviation. Asterisk indicates significant group differences $\left({ }^{*} P<0.05\right)$.

of these beverages than children who seldom had these beverages in the home. The availability of fruits and vegetables has consistently been found to be a predictor of actual intake ${ }^{(7,8,28)}$; however, we found no significant differences between household fruit and vegetable availability and children's consumption. Unlike beverages which can be easily poured from a container, fruits and vegetables may not be consumed by children who do not have the skills or knowledge to prepare them. Children who often had fruits and vegetables in the home were more likely to have milk in the home and vegetables on their plate at dinner, whereas children who often had soda in the home were more likely to often have potato chips in the home. These results suggest a coupling of healthy or unhealthy eating behaviours in Cree families.

The average household size where Cree children lived was more than double the national Canadian average of $2 \cdot 6$ persons per household ${ }^{(29)}$. Household crowding is a known determinant of poor health in Aboriginal communities ${ }^{(30)}$. Household size can influence household food purchasing $^{(31)}$, yet we found no association between household number and dietary variables. Approximately $20 \%$ of Cree mothers in northern Québec worry about having enough money to buy food for their children ${ }^{(32)}$. Cree children, regardless of household size, may experience all or most aspects of food insecurity due to limited economic opportunities in the communities, the high cost of market food, and limited food choices ${ }^{(32)}$. There is an inverse relationship between the energy density of food and its cost ${ }^{(33)}$. For this reason, diets comprised of energy-dense foods may be more affordable for families with food insecurity ${ }^{(33)}$. Studies in the USA and Canada have found differences in the price and availability of foods in lower-income neighbourhoods and communities; healthier foods generally are more expensive and less readily available ${ }^{(34)}$. Poverty limits access to healthful foods and increases exposure to unhealthy foods, and may be a direct cause of obesity in Cree children ${ }^{(33)}$.

\section{Limitations}

The present study had a cross-sectional design that allowed us to report observations but not causal relationships. A longitudinal study would be required to appreciate the contribution of restaurant meals and the home food environment to obesity in Cree children. There is the risk of respondent bias when using self-reported measures of dietary intake and behaviours. A potential limitation of the study was that children were asked food availability questions that were intended to be administered to parents; however, our results suggest that children were accurately reporting their home food environment as intake of beverages was associated with home availability.

\section{Conclusion}

Interventions to improve healthy eating among Aboriginal children should target determinants of health. 
Improved access and availability to traditional foods and market foods of high nutritional value will give Cree the opportunity to make healthy choices. The nutrition environment as a whole must be targeted to ensure the adoption of healthy eating ${ }^{(35)}$. Food-based changes to improve micronutrient intakes, such as increased milk, fruit and vegetable, and traditional food promotion, are required.

\section{Acknowledgements}

Sources of funding: The research was funded by an operating grant from the Canadian Institutes of Health Research (CIHR), Institute of Nutrition, Metabolism and Diabetes (INMD) and by a New Emerging Team grant from CIHR (INMD), in partnership with the Heart and Stroke Foundation of Canada. N.D.W. and K.D.R. acknowledge the Alberta Heritage Foundation for Medical Research for salary support and S.M.D. acknowledges the Alberta ACADRE Network (CIHR) for financial support. Conflict of interest declaration: None declared. Authorship responsibilities: S.M.D. participated in data collection, data analysis and manuscript preparation. A.A. participated in study design, data collection and collaborated on manuscript preparation. D.M. participated in study conceptualization and collaborated on manuscript preparation. K.D.R. participated in study design and collaborated on manuscript preparation. L.J.M. participated in study design and collaborated on manuscript preparation. N.D.W. led the research team and participated in all phases of this study. Acknowledgements: We wish to thank the Cree Board of Health and Social Services of James Bay, the communities involved and all of the participating children and their families.

\section{References}

1. Shields M (2005) Measured Obesity: Overweight Canadian children and adolescents. http://www.statcan.ca/english/ research/82-620-MIE/2005001/pdf/cobesity.pdf (accessed January 2006).

2. Wang $Y$ \& Lobstein $T$ (2006) Worldwide trends in childhood overweight and obesity. Int J Pediatr Obes 1, 11-25.

3. Bowman SA, Gortmaker SL, Ebbeling CB, Pereira MA \& Ludwig DS (2004) Effects of fast-food consumption on energy intake and diet quality among children in a national household survey. Pediatrics 113, 112-118.

4. Garriguet D (2006) Nutrition: Findings from the Canadian Community Health Survey, Overview of Canadians' Eating Habits. http://www.statcan.ca/english/research/82-620-MIE/ 82-620-MIE2006002.pdf (accessed November 2006).

5. Prentice AM \& Jebb SA (2003) Fast foods, energy density and obesity: a possible mechanistic link. Obes Rev $\mathbf{4}$, 187-194.

6. Anderson PM \& Butcher KE (2006) Childhood obesity: trends and potential causes. Future Child 16, 19-45.

7. Hanson NI, Neumark-Sztainer D, Eisenberg ME, Story M \& Wall M (2005) Associations between parental report of the home food environment and adolescent intakes of fruits, vegetables and dairy foods. Public Health Nutr 8 , $77-85$.

8. Davis M, Baranowski T, Resnicow K, Baranowski J, Doyle C, Smith M, Wang DT, Yaroch A \& Hebert D (2000) Gimme 5 fruit and vegetables for fun and health: process evaluation. Health Educ Behav 27, 167-176.

9. Willows ND (2005) Overweight in Aboriginal children: prevalence, implications and solutions. $J$ Aboriginal Health 2, 76-85.

10. Story M, Stevens J, Himes J, Stone E, Rock BH, Ethelbah B \& Davis S (2003) Obesity in American-Indian children: prevalence, consequences, and prevention. Prev Med 37, Suppl., S3-S12.

11. Frohlich KL, Ross N \& Richmond C (2006) Health disparities in Canada today: some evidence and a theoretical framework. Health Policy 79, 132-143.

12. Popkin BM \& Gordon-Larsen P (2004) The nutrition transition: worldwide obesity dynamics and their determinants. Int J Obes Relat Metab Disord 28, Suppl. 3, S2-S9.

13. Willows ND (2005) Determinants of healthy eating in Aboriginal peoples in Canada: the current state of knowledge and research gaps. Can J Public Health 96, Suppl. 3, S32-S41.

14. Kuhnlein HV, Receveur O, Soueida R \& Egeland GM (2004) Arctic indigenous peoples experience the nutrition transition with changing dietary patterns and obesity. J Nutr $\mathbf{1 3 4}$, 1447-1453.

15. Pong RW \& Pitblado JR (2001) Don't take 'geography' for granted! Some methodological issues in measuring geographic distribution of physicians. Can J Rural Med $\mathbf{6}$, 103-112.

16. Cole TJ, Bellizzi MC, Flegal KM \& Dietz WH (2000) Establishing a standard definition for child overweight and obesity worldwide: international survey. BMJ 320, $1240-1243$.

17. Gibson RS (2005) Principles of Nutritional Assessment, 2nd ed. New York: Oxford University Press.

18. Institute of Medicine (2000) Dietary Reference Intakes: Applications in Dietary Assessment. Washington, DC: National Academy Press.

19. First Nations Centre (2005) Children's survey: Preliminary findings of the First Nations Regional Longitudinal Health Survey (RHS) 2002-03. http://www.health-disciplines.ubc. $\mathrm{ca} / \mathrm{iah} /$ acadre/site_files/resources/RHS_preliminary_adult_ sept_9_04.pdf (accessed September 2006).

20. Trifonopoulos M, Kuhnlein HV \& Receveur O (1998) Analysis of 24-hour recalls of 164 fourth- to sixth-grade Mohawk children in Kahnawake. J Am Diet Assoc 98, 814-816.

21. Stroehla BC, Malcoe LH \& Velie EM (2005) Dietary sources of nutrients among rural Native American and white children. J Am Diet Assoc 105, 1908-1916.

22. Berti PR, Hamilton SE, Receveur O \& Kuhnlein HV (1999) Food use and nutrient adequacy in Baffin Inuit children and adolescents. Can J Diet Pract Res 60, 63-70.

23. Kuhnlein HV, Soueida R \& Receveur O (1996) Dietary nutrient profiles of Canadian Baffin Island Inuit differ by food source, season, and age. J Am Diet Assoc 96, 155-162.

24. Kuhnlein HV \& Receveur O (2007) Local cultural animal food contributes high levels of nutrients for Arctic Canadian Indigenous adults and children. J Nutr 137, 1110-1114.

25. Zoumas-Morse C, Rock CL, Sobo EJ \& Neuhouser ML (2001) Children's patterns of macronutrient intake and associations with restaurant and home eating. J Am Diet Assoc 101, 923-925.

26. French SA, Story M, Neumark-Sztainer D, Fulkerson JA \& Hannan P (2001) Fast food restaurant use among adolescents: associations with nutrient intake, food choices and 
behavioral and psychosocial variables. Int $J$ Obes Relat Metab Disord 25, 1823-1833.

27. Gable S \& Lutz S (2000) Household, parent, and child contributions to childhood obesity. Fam Relat 49, 293-300.

28. Haire-Joshu D \& Nanney MS (2002) Prevention of overweight and obesity in children: influences on the food environment. Diabetes Educ 28, 415-423.

29. Statistics Canada (2002) Profile of Marital Status, CommonLaw Status, Families, Dwellings and Households, for Canada, Provinces, Territorities, Census Divisions and Census Subdivisions, 2001 Census. 95F0487XCB2001001. Ottawa: Statistics Canada.

30. Government of Canada (2004) Canada's performance, annual report to parliament. http://www.tbs-sct.gc.ca/report/ govrev/04/dwnld/cp-rc_e.pdf (accessed January 2006).
31. Ricciuto L, Tarasuk V \& Yatchew A (2006) Socio-demographic influences on food purchasing among Canadian households. Eur J Clin Nutr 60, 778-790.

32. Willows ND, Iserhoff R, Napash L, Leclerc L \& Verrall T (2005) Anxiety about food supply in Cree women with infants in Quebec. Int J Circumpolar Health 64, 55-64.

33. Drewnowski A \& Specter SE (2004) Poverty and obesity: the role of energy density and energy costs. Am J Clin Nutr 79, 6-16.

34. Cummins S \& Macintyre S (2006) Food environments and obesity - neighbourhood or nation? Int J Epidemiol 35, 100-104.

35. Glanz K, Sallis JF, Saelens BE \& Frank LD (2005) Healthy nutrition environments: concepts and measures. Am J Health Promot 19, 330-333. 